\title{
Produção de cebola orgânica em função do uso de cobertura morta e torta de mamona
}

\author{
Silvio da S Santos'; José Antonio A Espíndola²; José Guilherme M Guerra²; Marco Antonio de A Leal²; \\ Raul de LD Ribeiro ${ }^{3}$

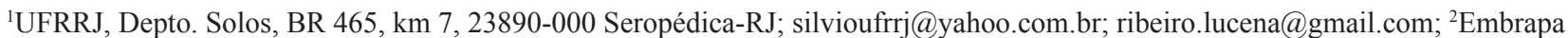 \\ Agrobiologia, BR 465 km 7, 23851-970 Seropédica-RJ; jose@cnpab.embrapa.br; gmguerra@cnpab.embrapa.br; mleal@cnpab.embrapa.br; \\ ${ }^{3}$ UFRRJ, Depto. Fitotecnia
}

\section{RESUMO}

A cebola é uma hortaliça consumida em grande quantidade e tem sua produção concentrada no âmbito da agricultura familiar, sendo responsável pela geração de emprego e renda para grande número de produtores rurais que tem no cultivo desta espécie sua única fonte de renda. É crescente a demanda por tecnologias para produção de cebola adequadas à agricultura familiar, com ênfase em técnicas agroecológicas. Neste aspecto, destaca-se a utilização de coberturas mortas e adubos orgânicos. O objetivo deste trabalho foi avaliar o efeito de diferentes coberturas mortas, associados a doses crescentes de torta de mamona aplicadas em cobertura, na produção total e no diâmetro dos bulbos de cebola produzidos em sistema orgânico. Observou-se efeito significativo da cobertura morta na produção total e nas diferentes classes de diâmetro de bulbo. Não foram observados efeitos significativos da adubação com a torta de mamona e da interação entre cobertura e adubação com torta de mamona. $\mathrm{O}$ efeito benéfico da cobertura morta na produtividade e na qualidade da cebola foi, provavelmente, decorrente da manutenção de maior umidade e da redução da amplitude térmica do solo.

Palavras-chave: Allium cepa, mulch, adubação orgânica.

\begin{abstract}
Production of organically grown onions depending on the use of mulch and castor bean cake

Onion is a highly consumed vegetable whose production is based on smallholder agriculture. The onion production is responsible for the generation of jobs and income for many farmers who have this as the only source of income. There is a growing demand for onion production technologies suitable for smallholders, with emphasis on agroecology. In this respect, we highlight the use of mulches and organic fertilizers. The aim of this study was to evaluate the effect of different mulches, associated to increasing doses of castor bean cake applied in side dressing on total production and diameter of onion bulbs grown in organic system. There was a significant effect of the mulch over the total yield and the yield obtained of different diameter classes of bulbs. There were no significant effects of side dressing with the castor bean cake, neither of the interaction between the mulch and the fertilization with castor bean cake. The beneficial effect of mulch which probably had more influence on the increasing of onion yield was the maintenance of moisture and reduction of soil temperature range.
\end{abstract}

Keywords: Allium cepa, mulch, organic manuring.

(Recebido para publicação em 28 de abril de 2011; aceito em 26 de julho de 2012) (Received on April 28, 2011; accepted on July 26, 2012)

A cebola é uma hortaliça com destacada importância socioeconômica, pois é um produto consumido em grande quantidade e tem sua produção concentrada no âmbito da agricultura familiar, sendo responsável pela geração de emprego e renda para grande número de produtores rurais que tem no cultivo da cebola sua única fonte de renda. Segundo Vilela et al. (2005), observam-se nos consumidores, preferências pela ótima qualidade do produto, diversificação de tipos varietais e produtos diferenciados, como os produzidos em sistemas orgânicos e agroecológicos.

É crescente a demanda por tecnologias para produção de cebola, adequadas à agricultura familiar, com ênfase em técnicas agroecológicas. Neste aspecto, destaca-se a utilização de coberturas mortas. De acordo com Magdoff \& Van Es (2000), as coberturas mortas promovem inúmeras vantagens, incluindo melhoria na capacidade de fornecimento de água para as culturas, proporcionando maior infiltração da água no solo e menor evaporação; controle de plantas expontâneas; menor variação da temperatura do solo; redução de salpicos de solo nas folhas e frutas dos produtos agrícolas e redução de pragas e doenças.

Diversos autores tem demonstrado o efeito positivo da utilização de coberturas mortas em hortaliças. Resende et al. (2005) observaram que o uso de cobertura morta de solo mostrou-se vantajoso para a cultura da cenoura em vários aspectos, sendo técnica e economicamente viável, principalmente, em pequenas áreas e em cultivos orgânicos.
Segundo Corrêa et al. (2003), a cobertura morta promoveu aumentos significativos no crescimento e na produtividade da cultura do alho, em relação ao solo descoberto. Adetunji (1994), estudando a resposta de cebola à cobertura do solo com casca de amendoim, serragem e forragem de milho, observou que, com exceção da cobertura com serragem, a cobertura do solo aumentou significativamente o crescimento vegetativo e a produção de bulbos de cebola.

A cebola é uma cultura que exige solos com elevada fertilidade e diversos autores têm relatado respostas positivas à utilização de adubos minerais e orgânicos (May et al, 2007; Resende \& Costa, 2008; Cecílio Filho et al, 2009). Kurtz \& Ernani (2010) observaram que a aplicação de $\mathrm{Zn}$ ao solo aumentou a 
produtividade de cebola cultivada em um Cambissolo Háplico Tb distrófico.

A cebola cultivada em sistema orgânico apresenta elevadas produtividades. Paula et al. (2009) obtiveram produtividade de 54,95 t ha-1 em cultivo orgânico realizado em um Argissolo Vermelho Amarelo. Belfort et al. (2006), avaliando 16 cultivares, obtiveram produtividades médias de 24,27 $\mathrm{t} \mathrm{ha}^{-1}$ para a cebola produzida em sistema convencional e produtividade média de $26,03 \mathrm{tha}^{-1}$ para cebola produzida em sistema orgânico.

De acordo com Castro et al. (2005), uma das principais dificuldades enfrentadas pela agricultura orgânica reside no aporte de nutrientes aos sistemas produtivos, principalmente o nitrogênio. O adubo orgânico deve apresentar elevado teor de nutrientes e capacidade para disponibilizar os nutrientes em velocidade compatível com a demanda da cultura. A torta de mamona é um adubo orgânico que possui estas características e por isto é muito utilizada na produção de hortaliças em sistemas orgânicos. Campos et al. (1963), relatam o efeito positivo da utilização de torta de mamona na adubação da cultura da cebola. Severino et al. (2004) demonstraram que a velocidade de mineralização da torta de mamona, medida pela respiração microbiana, é cerca de seis vezes maior que a do esterco bovino e quatorze vezes maior que a do bagaço de cana.

O objetivo deste trabalho foi avaliar o efeito da utilização de coberturas mortas, associadas a doses crescentes de torta de mamona aplicadas em cobertura, na produção total e no diâmetro dos bulbos de cebola produzidos em sistema orgânico.

\section{MATERIAL E MÉTODOS}

O experimento foi conduzido de maio a outubro de 2009, em uma área do Sistema Integrado de Produção Agroecológica $\left(22^{\circ} 45^{\prime} \mathrm{S}, 4^{\circ} 54^{\prime} \mathrm{W}, 33\right.$ $\mathrm{m}$ de altitude), localizada no município de Seropédica $(\mathrm{RJ})$. O clima da região pertence à classe Aw, segundo Köppen. O solo da área experimental foi classificado como Argissolo Vermelho Amarelo. A análise de fertilidade da camada de 0-20 cm apresentou: $\mathrm{pH}\left(\mathrm{H}_{2} \mathrm{O}\right)=6,2$; $\mathrm{Al}=0,0 \mathrm{cmol}_{\mathrm{c}} \mathrm{dm}^{-3} ; \mathrm{P}=58,9 \mathrm{mg} \mathrm{dm}^{-3} ; \mathrm{K}=$
$300 \mathrm{mg} \mathrm{dm}^{-3} ; \mathrm{Ca}=2,9 \mathrm{cmol}_{\mathrm{c}} \mathrm{dm}^{-3} ; \mathrm{Mg}=$ $1,6 \mathrm{cmol}_{\mathrm{c}} \mathrm{dm}^{-3}$; e $13,3 \mathrm{~g} \mathrm{~kg}^{-1}$ de matéria orgânica.

O delineamento experimental adotado foi blocos casualizados com 12 tratamentos e quatro repetições. Os tratamentos foram dispostos em arranjo fatorial $3 \times 4$, em que avaliaram-se 3 coberturas mortas do solo (bambu (Bambuza sp.), gliricídia (Gliricidia sepium) e um tratamento controle (ausência de cobertura do solo); e quatro doses de adubação de cobertura com torta de mamona. A cebola foi cultivada em canteiros de 1,0 m de largura, e cada parcela experimental ocupou 1,8 $\mathrm{m}$ de comprimento, reunindo seis linhas transversais de plantio, espaçadas em 30 $\mathrm{cm}$. A densidade de plantas adotada foi de 20 plantas $/ \mathrm{m}$. As avaliações foram realizadas em 28 plantas localizadas no centro de cada parcela.

As mudas de cebola, cultivar Alfa Tropical, foram produzidas em casa-de-vegetação, utilizando bandejas de poliestireno expandido com 288 células. Utilizou-se substrato obtido com a mistura de esterco bovino, húmus de minhoca e argila, na proporção de 1:1:1 (v/v). As mudas foram transplantadas para os canteiros aos 43 dias após semeadura. Com base na análise do solo e nas recomendações encontradas em Almeida et al. (1988), foi efetuada uma adubação dos canteiros, antes do transplantio das mudas de cebola, aplicando-se 10,0 t $\mathrm{ha}^{-1}$ de esterco bovino curtido (massa seca), contendo 11,0 $\mathrm{g} \mathrm{kg}^{-1}$ de N, 3,93 g $\mathrm{kg}^{-1}$ de P, 8,25 $\mathrm{g} \mathrm{kg}^{-1}$ de $\mathrm{K}, 11,80 \mathrm{~g} \mathrm{~kg}^{-1}$ de $\mathrm{Ca}$ e 5,45 $\mathrm{g} \mathrm{kg}^{-1}$ de $\mathrm{Mg}$. A adubação de cobertura com torta de mamona foi realizada aos 21 dias após o transplantio, com doses de 0, 100, 200 e $300 \mathrm{~g} \mathrm{~m}^{-2}$, quantidades estas equivalentes à aplicação de $0,50,100$ e $150 \mathrm{~kg}$ de $\mathrm{N} \mathrm{ha}^{-1}$.

Os materiais utilizados como cobertura morta do solo foram provenientes de folhas e pecíolos resultantes da poda da parte aérea da gliricídia e, no caso do bambu, aproveitaram-se folhas provenientes do processo natural de senescência desta espécie. Antes da aplicação nos canteiros, estes materiais foram secos em local sombreado e arejado.

A aplicação da cobertura morta foi efetuada 22 dias após o transplantio da cebola nos canteiros. Com isso, evitou- -se um possível efeito prejudicial dos resíduos vegetais sobre as mudas de cebola em sua fase inicial de desenvolvimento. Aplicou-se $3,1 \mathrm{~kg} \mathrm{~m}^{-2}$ de gliricídia e $2,6 \mathrm{~kg} \mathrm{~m}^{-2}$ de folhas de bambu, valores de massa fresca equivalentes a 2,0 $\mathrm{kg} \mathrm{m}^{-2}$ de massa seca de cada material. Imediatamente após a distribuição, a área experimental foi irrigada, visando a acomodação da cobertura morta, evitando sua eventual remoção pelo vento.

Foram realizadas irrigações por aspersão convencional durante todo o ciclo da cebola. O controle de ervas espontâneas foi realizado manualmente, quando necessário, visando evitar competição. A colheita da cebola foi realizada aos 160 dias após a semeadura. Os bulbos colhidos permaneceram por um período de sete dias em local com umidade e temperatura adequadas, até a cura total dos mesmos. Após esse período, os bulbos foram quantificados em termos de produtividade e foi realizada a classificação de acordo com o diâmetro transversal (Paula, 2003): classe $1(\varnothing \leq 30 \mathrm{~mm}), 2(30<\varnothing<50 \mathrm{~mm})$, $3(50 \leq \varnothing<70 \mathrm{~mm})$ e $4(\varnothing \geq 70 \mathrm{~mm})$. Os dados obtidos foram submetidos à análise de variância utilizando-se o teste $\mathrm{F}$ e comparações de médias utilizando-se o teste Scott-Knott.

\section{RESULTADOS E DISCUSSÃO}

Observou-se efeito significativo da cobertura morta na produção total e na produção obtida em diferentes classes de diâmetro de bulbo. Não foram observados efeitos significativos da adubação de cobertura com a torta de mamona e da interação entre cobertura morta e adubação com torta de mamona.

Observa-se na Tabela 1 que os tratamentos com cobertura morta apresentaram produções totais significativamente superiores ao tratamento ausência de cobertura. $\mathrm{O}$ tratamento cobertura com palha de bambu apresentou produtividade de 26,49 t ha-1 e o tratamento cobertura com palha de gliricídia apresentou produtividade de 25,04 $\mathrm{t} \mathrm{ha}^{-1}$, ambas superiores à produtividade média nacional de cebola, que foi de 22,09 $\mathrm{tha}^{-1} \mathrm{em}$ 2009 (IBGE, 2009), e que representam aumentos de 90 e $79 \%$, respectivamente, em relação à produtividade apresentada 
Tabela 1. Produção total e produção obtida em diferentes classes de diâmetro de bulbo, de cebola orgânica cultivada com o uso de diferentes coberturas mortas (total production and production obtained in different diameter classes of organic onion grown with the use of different mulches). Seropédica, UFRRJ, 2009.

\begin{tabular}{lccccc}
\hline Fonte da cobertura morta & Produção total & $\begin{array}{c}\text { Classe } \mathbf{1} \\
(\boldsymbol{\emptyset} \leq \mathbf{3 0} \mathbf{~ m m})\end{array}$ & $\begin{array}{c}\text { Classe 2 } \\
(\mathbf{3 0}<\boldsymbol{\emptyset}<\mathbf{5 0} \mathbf{~ m m})\end{array}$ & $\begin{array}{c}\text { Classe } \mathbf{3} \\
(\mathbf{5 0} \leq \boldsymbol{\emptyset}<\mathbf{7 0} \mathbf{~ m m})\end{array}$ & $\begin{array}{c}\text { Classe 4 } \\
(\boldsymbol{\emptyset} \geq \mathbf{7 0} \mathbf{~ m m})\end{array}$ \\
\hline Palha de bambu & $26,49 \mathrm{~A}$ & $2,02 \mathrm{~B}$ & $5,08 \mathrm{~B}$ & $15,89 \mathrm{~A}$ & $3,50 \mathrm{~A}$ \\
Palha de gliricídia & $25,04 \mathrm{~A}$ & $2,23 \mathrm{~B}$ & $7,97 \mathrm{~A}$ & $13,35 \mathrm{~A}$ & $1,49 \mathrm{~A}$ \\
Ausência de cobertura & $13,96 \mathrm{~B}$ & $2,82 \mathrm{~A}$ & $5,92 \mathrm{~B}$ & $5,22 \mathrm{~B}$ & $0,00 \mathrm{~A}$ \\
\hline CV $(\%)$ & 26,11 & 39,15 & 33,14 & 45,34 & 244,77 \\
\hline
\end{tabular}

Médias seguidas de diferentes letras são significativamente diferentes $(\mathrm{p} \leq 0,05)$ pelo teste Scott-Knott (average values followed by different letters are significantly different, Scott-Knott test $5 \%$ ).

pelo tratamento ausência de cobertura.

A utilização de cobertura morta também influenciou significativamente na produção obtida em diferentes classes de diâmetro de bulbo de cebola (Tabela 1). Os tratamentos cobertura com palha de bambu e cobertura com palha de gliricídia proporcionaram maior produção que o tratamento ausência de cobertura nas classes 3 e 4, de maior diâmetro de bulbo, enquanto que na classe 1 , de menor diâmetro de bulbo, ocorreu o inverso. Isto evidencia que a utilização de cobertura morta promoveu a produção de cebolas com maiores diâmetros de bulbo.

Não se observou diferença significativa entre os tratamentos palha de bambu e palha de gliricídia, apesar de a palha de gliricídia apresentar maior conteúdo de nitrogênio $\left(35,1 \mathrm{~g} \mathrm{~kg}^{-1}\right.$ de $\left.\mathrm{N}\right)$ que a palha de bambu $\left(11,8 \mathrm{~g} \mathrm{~kg}^{-1}\right.$ de $\left.\mathrm{N}\right) \mathrm{e}$ maior velocidade de decomposição. Oliveira et al. (2008), estudando diferentes coberturas mortas na cultura da alface, observaram, após 35 dias, que a palha de bambu apresentou $82,5 \%$ da massa seca e $82,9 \%$ de nitrogênio remanescentes, enquanto que a palha de gliricídia apresentou $51,4 \%$ da massa seca e $41,9 \%$ de nitrogênio remanescentes.

$\mathrm{O}$ efeito benéfico da cobertura morta na produtividade e na qualidade da cebola foi, provavelmente, decorrente da manutenção de maior umidade e da redução da amplitude térmica do solo, haja vista que o experimento foi conduzido no período mais seco do ano, com precipitações mensais inferiores a $100 \mathrm{~mm}$ e com ocorrência de grandes amplitudes diárias de temperatura e de umidade do ar. Segundo Muller (1991), a cobertura morta tem sido utilizada em cultivos de hortaliças com o intuito de reduzir a desagregação do solo, incidência de plantas espontâneas, além de contribuir para menores amplitudes térmicas e a manutenção da umidade do solo em níveis adequados para o desenvolvimento das plantas.

A ausência de efeito significativo da aplicação de doses crescentes de torta de mamona em cobertura sobre a produção total de cebola ocorreu, provavelmente, devido à elevada fertilidade do solo e também devido à utilização de 10,0 t $\mathrm{ha}^{-1}$ de esterco bovino curtido aplicado como adubação de base, proporcionando estoques de nutrientes suficientes para que a cebola se desenvolvesse sem qualquer carência nutricional. A aplicação de doses crescentes de torta de mamona em cobertura também não influenciou significativamente na produção obtida em diferentes classes de diâmetro de bulbo de cebola.

\section{REFERÊNCIAS}

ADETUNJI IA. 1994. Response of onion to solarization and organic mulching in semi-arid tropics. Scientia Horticulturae 60: 161-166.

ALMEIDA DL; SANTOS GA; DE POLLI H; CUNHA LH; FREIRE LR; AMARAL SOBRINHO NMB; PEREIRA NNC; EIRA PA; BLOISE RM; SALEK RC. In: DE POLLI H. (coord). Manual de Adubação para o Estado do Rio de Janeiro. Itaguaí: Editora Universidade Rural. 1988. 179p.

BELFORT G; NAKADA PG; SILVA DJH; DANTAS GG; SANTOS RRH. 2006. Desempenho de cultivares de cebola nos sistemas orgânico e convencional em Minas Gerais. Horticultura Brasileira 24: 206-209.

CAMPOS RH; PRADO OT; VENTURINI WR. 1963. Sistema de aplicação de torta de mamona e fertilizantes minerais na adubação da cebola. Bragantia 22: 259-265.

CASTRO CM; ALMEIDA DL; RIBEIRO RLD; CARVALHO JF. 2005. Plantio direto, adubação verde e suplementação com esterco de aves na produção orgânica de berinjela. Pesquisa Agropecuária Brasileira 40: $495-$ 502.

CECÍLIO FILHO AB; MAY A; PÔRTO DRQ; BARBOSA JC. 2009. Crescimento da cebola em função de doses de nitrogênio, potássio e da população de plantas em semeadura direta. Horticultura Brasileira 27: 49-54.

CORREAA TM; PALUDO SK; RESENDE FV; OLIVEIRA PSR. 2003. Adubação química e cobertura morta em alho proveniente de cultura de tecidos. Horticultura Brasileira 21: 601-604.

IBGE-INSTITUTO BRASILEIRO DE GEOGRAFIA E ESTATÍSTICA. Confronto das Safras de 2009 e 2010. Disponível em http://www.ibge.gov.br/home/estatistica/ indicadores/agropecuaria/lspa/lspa_201007_6. shtm Acesso em 25 ago. 2010.

KURTZ C; ERNANI PR. 2010. Produtividade de cebola influenciada pela aplicação de micronutrientes. Revista Brasileira de Ciências de Solo 34: 133-142.

MAGDOFF FR; Van ES, HM. 2000. Building soils for better crops. Handbook Series Book 4. Sustainable Agriculture Network, Beltsville, MD. 230p.

MAY A; CECÍLIO FILHO AB; PORTO DRQ; VARGAS PF; BARBOSA JC. 2007. Produtividade de híbridos de cebola em função da população de plantas e da fertilização nitrogenada e potássica. Horticultura Brasileira 25: 53-59.

MULLER AG. 1991. Comportamento térmico do solo e do ar em alface (Lactuca sativa L.) para diferentes tipos de cobertura do solo. Piracicaba: ESALQ, 77p. (Tese mestrado).

OLIVEIRA FF; GUERRA JGM; ALMEIDA DL; RIBEIRO RLD; ESPINDOLA JAA; RICCI MSF; CEDDIA MB. 2008. Avaliação de coberturas mortas em cultura de alface sob manejo orgânico. Horticultura Brasileira 26: 216-220.

PAULA PD. 2003. Desempenho de cultivares de cebola (Allium cepa L.) sob manejo orgânico no estado do Rio de Janeiro. Seropédica: UFRRJ, 73p. (Tese mestrado).

PAULA PD; GUERRA JGM; RIBEIRO RLD; CESAR MNZ; GUEDES RE; POLIDORO JC. 2009. Viabilidade agronômica de consórcios entre cebola e alface no sistema orgânico de produção. Horticultura Brasileira 27: 
202-206.

RESENDE GM; COSTA ND. 2008. Épocas de plantio e doses de nitrogênio e potássio na produtividade e armazenamento da cebola. Pesquisa Agropecuária Brasileira 43: 221226.

RESENDE FV; SOUZA LS; OLIVEIRA PSR; GUALBERTO R. 2005. Uso de cobertura morta vegetal no controle da umidade e temperatura do solo, na incidência de plantas invasoras e na produção da cenoura em cultivo de verão. Ciência e Agrotecnologia 29: 100-105.

SEVERINO LS; COSTA FX; BELTRÃO NEM; LUCENA AMA; GUIMARÃES MM.B. 2004. Mineralização da torta de mamona, esterco bovino e bagaço de cana estimada pela respiração microbiana. Revista de Biologia e
Ciências da Terra, 5, http://redalyc.uaemex. $\mathrm{mx} /$ redalyc/pdf/500/50050105.pdf Acesso em: 24 de agosto de 2010.

VILELA NJ; MAKISHIMA N; OLIVEIRA VR; COSTA ND; MADAIL JCM; CAMARGO FILHO W; BOEING G; MELO PCT. 2005. Desafios e oportunidades para o agronegócio de cebola no Brasil. Horticultura Brasileira 23: 1029-1033. 